\title{
Editorial: Education for What Purpose?
}

\author{
ANA AGOSTINO AND \\ WENDY HARCOURT
}

This final issue of Development Volume 53 looks at education as one of the core pathways to human sustainable development. As the articles reveal, there are many ways to understand the purposes of education. Is it to socialize future citizens or to prepare future workers to be more skilled, more efficient, better equipped to contribute to a growing economy? Is it about transforming society to be more democratic, more egalitarian, more gender-balanced, less prejudiced and more just? Is it about ensuring that all children, particularly in the poor communities of the Global South, attend school, with better trained teachers, with schooling kept to standards and measurable results? Is it about opening up peoples' creative potential throughout their lives so they are more responsible citizens? Is it about introducing to learners the richness of different knowledge systems that make up our global consciousness as we learn to respect nature and other living beings?

As you read through the articles you realize that education has to be understood as a mix of all of the above. Who sets the standards, who delivers, who learns, what is learned, how knowledge is built and shared, where it is happening, and how much and where the funds are coming from, are all key factors affecting how education is perceived and practiced.

As you reflect on the different approaches, concerns, hopes, and goals of educational work of the various authors, what emerges are the deep sensitivities around education in the field of development. The challenge is to read the articles with an open mind in order to see how education, like development, means many things to many people.

When we were reviewing the articles we imagined how fascinating it would be to convene the authors to engage in dialogue around their visions of education and imagine how to go forward in practice. It might well be that a common reference point would be the UN vision of education for sustainable development and the need to meet and surpass the Millennium Development Goals. Most would say education is key to human sustainable development. All would say it is about the rights of all to education and to developing a culture of education in all countries of the world. But how authors envisage putting those rights and culture into practice would no doubt be highly diverse. 
Several of the authors focus on the practical engagement with governments to deliver education in poor communities or in conflict zones and whether education helps or hinders efforts to eradicate poverty and pursue peace. Others open up questions about what universities should deliver for economies in the Global South, and where the emphasis of education should be in emerging economies.

Another set of authors engage much more broadly with concerns about how to work with learners of all ages in non-western cultures and communities. They look at popular and informal education as examples of how to make learning relevant to those often unable to benefit from mainstream education. They depict education transforming lives and communities in ways that are shaped by the learners themselves, following Paulo Freire's theory of the pedagogy of the oppressed. Other authors puzzle out how to address gender gaps not only in the numbers of girls receiving education, or women teachers, but also suggest that gender inequality can be redressed through the right kind of education and a culture which ensures that girl children exercise their right to education. All of the authors, whether implicitly or explicitly, speak to broad social, economic and political issues revealing how education is part and parcel of the larger development process. Though authors depending on where they are located, and what their perspectives are, differ as to how well that process is succeeding.

When the editorial team decided to put together this issue, we wanted to focus on education as transformative, following our journal's editorial approach that explores development in all its facets as a political process. We welcomed the generous partnership of the Academy for Educational Development (AED), which has supported past journal dialogues and plans to sponsor the launch of the issue in East Africa. The Local/Global Encounters section was put together by Mark Ginsburg and Mary Joy Pigozzi and draws on the vast practical experience of AED staff and their government and non-governmental partners around the world. That experience complements the other set of articles featured in the first Thematic Section introduced by Ana Agostino that looks at lifelong learning and explores examples of creative transformative learning at different life stages as well as the political process around the sixth UN International Conference on Adult Education.

As editor and associative editor we have enjoyed some interesting conversations as we compared the different approaches to transforming education and education for transformation raised by the authors. Along the way we discussed experiences in our own lives as mothers having to make educational choices. We found we shared similar concerns at how public education is being neglected as a result of the trend to privatize education and treat it as a 'service'.

What we both agree on is that the journal taps into the huge possibilities of education as a global institution and process that not only needs to ensure quality education but also is key to the transformation of society. In this Paulo Freire's emphasis on dialogue, based on respect for all people, seems to fit very well the journal's editorial approach. Education in this vision is part of a praxis of learning and action with the aim to make a positive difference in the world. His idea of building a 'pedagogy of hope' continues to inspire. The question is how to develop through education processes the 'global consciousness' which can fulfil the collective hope expressed in the journal to achieve human sustainable development.

Naming, somehow, is a way of constructing another reality. And, as this journal shows, there are multiple ways of naming 'education' and 'transformation' which in many occasions might seem to contradict each other but are an expression of diversity and of many different cultures and ideologies. These various approaches to education in 'praxis' show the importance of recognizing that there are different types of knowledge and ways of producing knowledge. They constitute a complex web that helps us move from understanding the world we live in to making it a better place to live for all. 